\title{
LITERATURA E MILITÂNCIA: A SOCIEDADE NA CRÍTICA DE ANTONIO CANDIDO
}

\section{LITERATURE AND ACTIVISM: SOCIETY IN ANTONIO CANDIDO'S CRITICS}

\author{
Ana Clara Vieira da Fonseca ${ }^{1}$
}

\begin{abstract}
RESUMO: Antonio Candido de Mello e Souza, considerado por muitos o maior representante da crítica e da historiografia literárias do Brasil, deixou um legado imensurável ao desenvolver, por meio da escrita, uma intervenção social cuja orientação primordial está na luta contra o pensamento estagnado e na constante busca pela contradição - que é o coração da vida em sociedade. Para Candido, a crítica literária dialética possibilita que se reconheça o papel da realidade e da tradição cultural no fazer literário. Retomando textos do livro Textos de intervenção, organizado por Vinícius Dantas, esta exposição tem o objetivo de realizar um breve percurso pela produção do autor e destacar pontos de sua crítica militante, acadêmica e, acima de tudo, de uma atualidade fascinante, de modo a homenageá-lo e fornecer ânimo para aqueles que continuam lutando por uma sociedade mais justa e esclarecida.
\end{abstract}

Palavras-chave: Literatura; militância; Antonio Candido; crítica literária; historiografia literária.

\begin{abstract}
Antonio Candido de Mello e Souza, considered by many the greatest representative of Brazil's critic and historiography literature, has left an invaluable legacy by engaging, by mean of writing, in a social intervention, which is centered in a conflict with stationary thought and constant search for contradiction - seen as the heart of life in society. According to Candido, dialectical literary critic enables the recognition of tradition and reality in the makings literary work. Revisiting texts from Textos de Intervenção, organized by Vinícius Dantas, this explanation aims to perform a short journey through Candido's production and highlight points from his activist, academic and, specially, contemporary critics as way to pay tribute and enhance the spirit of those who continue to battle of a more fair and enlightened society.
\end{abstract}

Keywords: Literature; Activism; Antonio Candido; Literary Critic; Literary Historiography.

\footnotetext{
${ }^{1}$ Mestra em Literatura vinculada à linha de pesquisa Crítica Literária Dialética do Programa de Pós-Graduação em Literatura da Universidade de Brasília (PósLIT/UnB). Bolsista de produtividade da CAPES. Membro do grupo de pesquisa Literatura e Modernidade Periférica. E-mail: anaclaravf@gmail.com.
} 


\section{INTRODUÇÃO}

Sociólogo e professor da Universidade de São Paulo, Antonio Candido de Mello e Souza é um dos maiores representantes da crítica e da historiografia literária desenvolvidas no Brasil do século XX. Sua escrita é uma forma de intervenção social que tem como diretriz principal a luta contra o pensamento estanque, a busca pela contradição que é o cerne da vida em sociedade. Candido vai além e se utiliza de sua atividade crítica para contestar espaços como a cátedra universitária e sua ordem institucional, além do papel limitador das grandes editoras, sempre com o objetivo de transformar tais instituições.

É por meio de sua crítica que o jovem Antonio Candido passa a fazer parte do grupo de intelectuais que cria a revista Clima, publicação com o objetivo de analisar a vida cultural brasileira sob a perspectiva da Sociologia, da Filosofia e da Antropologia; além disso, o professor se consolida como crítico literário ao publicar ensaios nos jornais Folha da Manhã e Diário de São Paulo.

Professor da Faculdade de Filosofia, Letras e Ciências Humanas, Antonio Candido tem, na USP, uma grande atuação contra o fascismo. Em um contexto no qual o corpo discente da Universidade passa a ser composto tanto por membros da classe alta quanto por indivíduos oriundos de uma classe média baixa, que veem na instituição uma oportunidade de crescimento e, adicionalmente, encontram um ambiente propício para a reflexão sobre sua posição social e origem, a produção intelectual passa a conter um direcionamento para a transformação da realidade à medida que elementos como a condição de vida do trabalhador brasileiro e a mobilização contrária ao Estado Novo se tornam mais recorrentes nos materiais publicados; é aqui que o papel político da Universidade de São Paulo se torna maior na luta contra o fascismo.

Candido teve um relacionamento complicado com as instituições de esquerda e o Partido Comunista de seu país. Ao perceber que a pós-graduação que ajudara a construir na USP se torna um ambiente em que o academicismo conduzia à afirmação individualista e a burocracia recebia mais atenção do que o espaço para a reflexão, Candido se afasta de sua posição e volta a lecionar apenas na graduação. Associada à sua repulsa pelo academicismo está sua posição contrária ao comunismo stalinista, o que leva ao momento em que se afasta do Partido Comunista Brasileiro e ajuda a fundar a Esquerda Democrática em São Paulo (que viria a se tornar o Partido Socialista Brasileiro).

É fundamental o papel da Antropologia para a formação de Antonio Candido; é por meio dela que o crítico chega ao conceito de cultura, do qual partem dois postulados 
determinantes para o desenvolvimento do seu pensamento: a sistematicidade das ações humanas e o da historicidade de todo o conhecimento, noções que o aproximam ainda mais da literatura e da sua possibilidade de funcionar como temática para toda avaliação social. É, portanto, unindo os conhecimentos empíricos, científicos e literários que Candido chega à escolha da literatura como tema central do seu discurso sobre a história cultural brasileira.

\section{Materiais e métodos}

Este artigo tem como proposta central desenvolver uma breve análise do livro Textos de Intervenção, escrito por Antonio Candido e organizado por Vinícius Dantas. Trata-se de um conjunto de textos inéditos que não foram publicados em volumes, apenas em colunas de jornais ou apresentados em discursos e materiais acadêmicos/políticos, reunidos de modo a evidenciar como funciona o conceito de crítica desenvolvido por Candido, mostrando as suas tendências e aquilo que defende nos seus textos, polêmicos e com viés público, sempre deixando evidentes as suas posições radicais.

\section{Discussões e resultados}

A combatividade e o conceito de sistema têm uma grande importância nos textos, os quais foram escritos em períodos delicados da política nacional. Candido foi capaz de desenvolver análises literárias sem fazê-las instrumento da política, mas sempre empregando perspectiva histórica e social; para ele, teoria e prática funcionam como uma unidade. O livro é dividido em quatro partes, a saber: Direções, Argumentos, Conduta e Conjuntura, conforme veremos a seguir.

Em Direções, são publicados textos que apresentam ao leitor a "paixão do concreto" que, segundo o crítico, seria a principal característica dos intelectuais de sua geração. Por isso, estão presentes nesta etapa artigos que demonstram o criterioso método de pesquisa de Candido, com levantamento minucioso de dados e processos técnicos, retomada de conceitos e noções importantes, com uma avaliação do universo particular de cada obra que o permite, em seguida, conectá-la a referências históricas e sociais. É interessante o destaque que Vinícius Dantas faz para o fato de que o estilo de Candido deixa claro o cuidado que o crítico toma para que o seu vocabulário de especialista não se sobreponha ao talento de escritor. Somos apresentados, assim, ao conceito de crítica funcional - "uma crítica que tendia a aferir as obras pelo grau de participação no destino de sua época" (CANDIDO, 2002, p. 17) - e à noção segundo a qual a 
literatura tem uma função compreensiva e humanizadora que é, em sua raiz, problemática, pois revela tensões e contradições psicológicas, sociais e formais sem tentar solucioná-las imediatamente. Além disso, é neste capítulo que fica claro o fato de que os problemas sociais e culturais estão relacionados a um processo histórico contraditório, incerto.

Para propor as aproximações iniciais, chamo a atenção para o artigo intitulado Notas de Crítica Literária - Ouverture, presente na primeira parte de Textos de Intervenção: Direções, que marca o início de suas publicações no jornal Folha da Manhã. Vinícius Dantas, em uma nota do organizador, esclarece que era comum no período a prática de propor diretrizes para uma coluna que ainda não tinha público definido. O que se encontra nesse artigo é uma reflexão acerca do que se deve esperar de um crítico, qual seria o papel do intelectual naquele contexto e em que consistiria a sua verdadeira tarefa. Nesse contexto, Candido diz não haver "crítica científica", visto que toda atividade crítica deve pressupor um relacionamento com a sociedade, e conclui que a tarefa do crítico estaria mais relacionada a poder integrar a significação de determinada obra em seu momento cultural do que a vê-la como origem de variações pessoais; além disso, seria possível tirar da obra uma orientação para a conduta em sociedade. Para o autor, mais valor tem um crítico partidário do que um "disponível”, visto que a disponibilidade intelectual seria um indício de falta de caráter.

Outro artigo da mesma seção o qual vale a pena ser destacado é Notas de Crítica Literária - Um ano. Nele, após um ano publicando em sua coluna do jornal Folha da Manhã, Candido retoma as diretrizes anteriormente traçadas para o trabalho e busca refletir se estaria seguindo aquilo a que se propusera. O autor diz que sempre buscou manter sua atividade crítica vinculada ao seu tempo, sempre relacionado as obras aos rumos que a inteligência moderna estaria seguindo. É destacada a importância de se desenvolver uma crítica participante e racional.

Em Argumentos, o foco está na análise de obras literárias mais intensivamente, é a crítica da produção contemporânea. Encontramos muitos textos da chamada crítica de rodapé, resenhas publicadas n'O Estado de São Paulo, uma apresentação a respeito da vanguarda; é, em suma, a verdadeira expressão do ensaísmo livre de Candido, textos em que encontramos debate e discussão com a característica força de exposição do crítico. Por meio desses textos, Candido conseguiu se apropriar de espaços pouco comuns para o exercício da crítica, como cantos de páginas em jornais, uma cerimônia de abertura em um evento de poetas, prefácio de um livro 
de memórias, mesas redondas e até o encarte do LP de Adoniran Barbosa. Aqui, é possível ver a crítica nos mais diversos meios e veículos.

O destaque vai para Discurso num congresso de poetas, proferido na abertura do I Congresso Paulista de Poesia (abril/1948). De acordo com Candido, existem duas vertentes no que tange à atuação do poeta: o escritor envolvido e atuante em questões sociais do seu tempo versus aquele que se distancia de tudo o que não seja pura abstração. Para autor, em seu tempo, ambos os lados possibilitaram o surgimento de poesia autêntica e merecedora de atenção; os novos poetas, aos quais Candido se refere, teriam em comum uma forte consciência crítica capaz de direcionar e regular suas tendências.

Na seção Conduta, os artigos estão organizados em dois blocos: o primeiro diz respeito ao material publicado em contexto de Segunda Guerra e fim do Estado Novo; o segundo apresenta textos publicados quase meio século depois, ao final do século XX. Em ambos os períodos, percebe-se a manutenção da coerência intelectual de Candido, sempre consciente de sua responsabilidade política e social, além do seu engajamento com questões importantes para a luta contra as formas reacionárias de pensamento - para o autor, o foco do combate da sua geração. Estão em pauta questões que chamam a atenção do leitor para os dilemas coletivos a serem enfrentados e para o empenho político dos intelectuais em atividade na década de 1930.

A ser doutrinário, Antonio Candido preferiu sempre ser socialista por inteiro. Em quase todos, senão todos, os textos desta seção, o ideal socialista pôde ser testado sem programa em situações práticas que produzem imaginação social, politização sem partidarização e ângulos novos, freqüentemente radicais, sobre misérias antigas e avanços reais, às vezes pouco evidentes, pressagiando possibilidades efetivas de socialismo em um mundo podre de desigualdade (DANTAS apud CANDIDO, 2002, p. 235).

Na referida seção, há um artigo intitulado Plataforma da Nova Geração. Em uma nota do organizador, Vinícius Dantas explica que Mário Neme realizou um inquérito publicado nas páginas de $O$ Estado de S. Paulo, com perguntas sobre o que poderia ser aproveitado como herança das gerações de poetas e críticos anteriores, se (e como) os seus modelos poderiam ser aproveitados, como a próxima geração poderia ser definida, etc. A resposta de Antonio Candido foi publicada no mesmo jornal e depois integrou o volume Plataforma da nova geração. Nesse texto, Candido realiza reflexões acerca da proposta: afinal, caberia definir o papel ou o dever da nova geração? 
Ao citar Carlos Drummond de Andrade, Candido defende que o poeta - membro da geração que Mário Nemer pretende julgar - é um exemplo único de sensibilidade com relação ao momento vivido, além de representar o "amadurecimento paralelo aos fatos" (CANDIDO, 2002, p. 239), o que o tornaria muito mais importante para a compreensão das gerações de intelectuais. Contudo, para Candido, a verdadeira literatura brasileira teria começado com a geração de 30, aquela que conseguiu moldar os intelectuais do porvir e direcionar sua orientação por meio das lutas políticas e sua atmosfera de crítica. A geração de Candido seria, portanto, crítica; seu dever estaria relacionado a combater, da melhor maneira possível, "todas as formas de pensamento reacionário" (CANDIDO, 2002, p. 245), pois ele impede que o progresso humano continue se expandindo. E o crítico continua: "Não nos compete, evidentemente, assumir uma cor política qualquer e descer à rua, clamando por ação direta. Cada um com as suas armas. A nossa é essa: esclarecer o pensamento e pôr ordem nas idéias" (CANDIDO, 2002, p. 245-246).

Outro texto da mesma seção que vale ser retomado é Alemanha = Nazismo?, no qual o crítico, motivado por uma afirmação de Radcliffe-Brown, propõe-se a refletir sobre a situação da Alemanha no pós-guerra e a luta contra o fascismo. De acordo com Radcliffe-Brown, professor de Oxford, a Alemanha deveria passar pelo castigo de ter o seu território retalhado como forma de "pagar" pelas atrocidades que teria cometido contra os países ocupados durante a Segunda Guerra Mundial, o que se justificaria visto que o professor julgava impossível uma reabilitação do povo alemão. Para Candido, são as condições históricas e mesológicas que determinam a inclinação de um povo, de modo que um povo guerreiro só poderia se tornar pacífico se as condições que o levam à guerra fossem substituídas por aquelas em que a paz seja possível. Assim, chegaria a época em que todos os povos da Europa se uniriam aos alemães para lutar contra o que restasse de nazismo e totalitarismo no continente. Candido defende que não se deve tentar vencer o fascismo usando os seus métodos, de modo que a solução é estender a mão à Alemanha para construir um mundo livre de fascismo.

O último texto de Conduta a ser citado aqui é Sobre a violência. Nesse artigo, Candido explica suas declarações a respeito da violência após ser acusado, por Miguel Reale, de ter defendido a prática em uma entrevista. Portanto, o crítico utiliza sua coluna na Folha da Manhã para esclarecer seu posicionamento. Ao ser questionado pelo entrevistador se era favorável à luta armada, Candido responde que a violência é uma possibilidade na ação política, mas não é essencial, de modo que o problema estaria na capacidade do político de decidir como e quando 
ela deve ser empregada. Assim, o crítico esclarece ser contra a violência pela violência, mas que a mesma é necessária quando a luta armada "se baseia numa concepção revolucionária correta e se traduz pela organização adequada" (CANDIDO, 2002, p. 289). É dito, ainda, que a violência tem sido usada, no Brasil e na maioria das vezes, pela direita e pelo centro, mas que é parte da ação política de esquerda também - com a diferença de que direita e centro achamna benéfica e legítima, mas seria intolerável o seu uso pela esquerda.

Na última seção, Conjuntura, estão compreendidos os textos nos quais Antonio Candido analisa a conjuntura política brasileira. São artigos publicados, principalmente, na Folha Socialista, vinculada ao Partido Socialista Brasileiro, o qual Candido ajudou a fundar. São intervenções clara e intensamente políticas, versando sobre temas como o parlamentarismo, o federalismo e o panorama nacional com relação aos partidos políticos, além de abordar as novas modalidades de fascismo que surgem no pós-guerra.

Quanto a essa seção, retomaremos apenas o artigo O tempo do contra. Aqui, Candido defende que sua geração estaria vivendo um período do contra, uma cultura contrária em muitos sentidos. São famílias em que os filhos são contra os avós, os pais, os irmãos; a moda costuma ser contrária ao que estava em vigor anteriormente; é, em suma, uma crise de civilização. $\mathrm{O}$ mesmo ocorre na arte, com relação ao surgimento das vanguardas e das tentativas de superação de estéticas anteriores. Para Candido, toda essa contrariedade tem sua origem no capitalismo:

[...] de um lado, situa um capitalismo, um capitalismo fortíssimo, um capitalismo extremamente poderoso, o capitalismo da era dos monopólios, e de outro lado coloca - como nunca houve em outro momento da história da humanidade - um desejo generalizado de igualdade, de distribuição equitativa dos bens, que é incompatível com esse capitalismo (CANDIDO, 2002, p. 372).

Portanto, sendo contra o capitalismo, Candido conclui que seremos, finalmente, a favor de alguma coisa: a favor dos movimentos contrários a esse capitalismo. Assim, qualquer movimento de abertura surge pois houve um movimento contra a opressão, a censura, a ditadura. 


\section{CONSIDERAÇÕES FINAIS}

Espera-se ter sido possível demonstrar que Textos de intervenção corresponde a valioso material em que se nota o percurso de um intelectual que não deixou a sua atuação restrita ao ambiente acadêmico; pelo contrário, percebemos Antonio Candido exercendo a atividade crítica de modo a intervir na sociedade, sempre tentando utilizar as suas ferramentas para esclarecer o pensamento, elucidar questões importantes e combater o pensamento reacionário, o fascismo e instituições opressoras.

\section{REFERÊNCIAS}

CANDIDO, Antonio. Textos de intervenção; seleção, apresentação e notas de Vinícius Dantas. São Paulo: Duas Cidades; Ed. 34, 2002.

Recebido em: 15 abr. 2018

Aceito em: 25 jun. 2018 